Do Moral Emotions Buffer the Anger-Aggression Link in Children and Adolescents?

Tyler Colasante, Antonio Zuffianò, and Tina Malti

Author Note

Tyler Colasante, Department of Psychology, University of Toronto Mississauga; Antonio Zuffianò, Department of Psychology, Fraser Mustard Institute for Human Development, University of Toronto Mississauga; Tina Malti, Department of Psychology, University of Toronto Mississauga.

This research was supported by grants from the Social Sciences and Humanities Research Council (SSHRC) and Canadian Institutes of Health Research (CIHR). The authors thank the children and caregivers who participated, and the members of the Laboratory for SocialEmotional Development and Intervention (SEDI) who helped with data collection, entry, and coding.

Correspondence concerning this article should be addressed to Tyler Colasante, Department of Psychology, University of Toronto Mississauga, 3359 Mississauga Rd, Mississauga, ON L5L 1C6. E-mail: tyler.colasante@ mail.utoronto.ca.

This is the peer-reviewed version of the following article: Colasante, T., Zuffianò, A., \& Malti, T. (2015). Do moral emotions buffer the anger-aggression link in children and adolescents? Journal of Applied Developmental Psychology, 41, 1-7. doi:10.1016/j.appdev.2015.06.001, which has been published by Elsevier. The final publication is available at Elsevier via http://dx.doi.org/10.1016/j.appdev.2015.06.001. Please refer to Elsevier Terms and Conditions of Archiving for more information: https://www.elsevier.com/about/company-information/policies/sharing. (C2015. This manuscript is licensed under the CC-BY-NC-ND License 4.0: https://creativecommons.org/licenses/by-nc-nd/4.0/ 


\begin{abstract}
Given the prevalence of anger-related aggression in school and out-of-school contexts, research on counteracting the anger-aggression link in children and adolescents is likely to have implications for educators and practitioners. Here, we tested moral guilt and sympathy as potential moderators of the anger-aggression link in a sample of 4-, 8-, and 12-year-olds $(N=$ 242). Caregivers reported their children's aggression and anger levels with a questionnaire. Children reported their moral guilt (in response to vignettes depicting intentional harm) and sympathy levels in an interview. Moral guilt and sympathy interacted with anger in relation to aggression. Controlling for age, sex, socio-economic status, and inhibitory control, high anger was significantly related to high aggression, but not when children and adolescents had high guilt or sympathy. We discuss the potential roles of moral guilt and sympathy in mitigating the angeraggression link.
\end{abstract}

Keywords: aggression, anger, moral guilt, sympathy, childhood, adolescence 
Do Moral Emotions Buffer the Anger-Aggression Link in Children and Adolescents?

Aggression in childhood and adolescence, such as fighting and teasing, has been linked to academic impairment (Brennan, Shaw, Dishion, \& Wilson, 2012), peer rejection (Ladd, Ettekal, Kochenderfer-Ladd, Rudolph, \& Andrews, 2014), and poor mental health outcomes (see Eisner \& Malti, 2015) for aggressors and victims. At the societal level, a lifetime case of untreated aggression costs taxpayers roughly $\$ 2.6$ to $\$ 4.4$ million (Cohen \& Piquero, 2009).

Given that aggressive behavior is often emotionally charged, developmental scientists have worked to identify its affective antecedents and thereby inform its early intervention (Arsenio \& Lemerise, 2010). In particular, the aggravating anger-aggression link (i.e., the notion that aggression is driven and exacerbated by unharnessed, angry feelings) has been well documented in children and adolescents (Lochman, Barry, Powell, \& Young, 2010). On the other hand, evidence suggests that moral feelings of guilt and sympathy highlight the negative consequences of aggression and protect against its development (Eisenberg, Spinrad, \& Morris, 2014; Malti, 2015). However, the interaction of these competing emotions has not been considered in light of aggressive behavioral outcomes. The extent to which moral emotions counteract the anger-aggression link remains unclear. We addressed this gap by investigating moral guilt and sympathy as potential moderators of 4-, 8-, and 12-year-olds' anger-related aggression. We chose these age groups to account for heightened moral-affective responding and behavioral functioning from childhood to adolescence (Malti \& Ongley, 2014), and to address the dearth of research on moral emotions and aggression in early childhood (see Malti \& Krettenauer, 2013).

\section{Anger and Aggression}


Aggressive behavior intentionally causes physical harm, psychological harm, or distress to others and is often associated with emotional states of anger (Krahé, 2013). Anger is an intense, affective reaction to threat or the perception of threat that involves a fight-or-flight response to an instigating stimulus (Lazarus, 1991). With the exception of moral anger (see Montada \& Schneider, 1989), research with various measures of anger and aggression seems to align with the frustration-aggression hypothesis (i.e., that anger and related arousal are expressed through overt aggressive behavior; Berkowitz, 1989). For example, high levels of anger have been associated with heightened forms of generalized aggression in children and adolescents (Arsenio, Cooperman, \& Lover, 2000; Lerner, Hertzog, Hooker, Hassibi, \& Thomas, 1988). In a longitudinal study by Eisenberg and colleagues (1999), children who displayed more frequent angry reactions during free play at study onset (ages 4 to 6) were rated as more aggressive by caregivers 2 and 4 years later. Anger has also been positively associated with reactive (i.e., provoked, defensive, and retaliatory) forms of aggression (Hubbard, Romano, McAuliffe, \& Morrow, 2010). In comparison to their less aggressive counterparts, reactively aggressive children have been shown to display more angry non-verbal cues and higher physiological arousal (e.g., skin conductance reactivity) during competitive, frustration-arousing activities (Hubbard et al., 2002).

\section{Moral Emotions and Aggression}

Unlike anger, moral emotions are thought to help children anticipate the negative consequences of aggression and adjust their behavior accordingly (Arsenio, 2014; Malti, 2015; Tangney, Stuewig, \& Mashek, 2007). In the present study, we focused on two distinct moral emotions of particular relevance to children's aggressive conduct: moral guilt and sympathy. Moral guilt is commonly referred to as regret over wrongdoing (Kochanska, Gross, Lin, \& 
Nichols, 2002; Malti \& Latzko, 2012). With the exception of neurotic guilt (i.e., inappropriate self-blame), guilty individuals rightly accept or anticipate responsibility for causing or associating themselves with a transgression of internalized moral norms (Hoffman, 2000). Developmental studies have utilized children's self-attributed, negative emotions following hypothetical moral transgressions to assess their guilt feelings in an experimental setting. Converging results from this paradigm have associated high levels of anticipatory guilt in contexts of moral transgression with low levels of aggressive conduct in early childhood (e.g., Dinolfo \& Malti, 2013) and across development (e.g., Malti, 2007). A recent meta-analytic review of 42 studies and over 8,000 participants between the ages of 4 and 20 found a significant, negative association $(d=.39)$ between moral guilt and aggressive behavioral outcomes, although it was recognized that relatively little research was conducted with samples from early childhood (Malti \& Krettenauer, 2013).

Sympathy, like empathy, stems from the apprehension of another's emotional state. Unlike empathy, it does not require experiencing the same or similar emotion(s) as the other. Sympathetic feelings are predominantly characterized by other-oriented sorrow or concern and are thought to heighten children's attention to the needs of others (Eisenberg, 2000a). A growing number of studies have documented a negative link between sympathy and aggressive behavior in childhood (e.g., Dinolfo \& Malti, 2013; Schultz, Izard, \& Bear, 2004; Strayer \& Roberts, 2004) and adolescence (Blair, 2010; Frick, 2012).

\section{Moral Emotions, Anger, and Aggression}

Our major goal was to assess moral emotions (i.e., guilt and sympathy) as potential buffers of the anger-aggression link in children and adolescents. Research on these competing emotions and aggressive behavioral outcomes is scarce. One previous study has investigated 
guilt and anger-related aggression (Tangney, Wagner, Hill-Barlow, Marschall, \& Gramzow, 1996). Nine- to 17-year-olds who rated themselves as more guilt prone were less likely to anticipate aggressive responses to hypothetical, anger-eliciting scenarios. To date, these results have not been extended to early childhood or corroborated with caregivers' reports of children's actual aggression. Moreover, the researchers did not control for children's and adolescents' regulatory capacities, which have been associated with low levels of anger (Frick \& Morris, 2004) and aggression (Eisenberg, Spinrad, \& Eggum, 2010). The anger-aggression buffering effects attributed to guilt-proneness may have actually stemmed from heightened regulation.

The combination of anger and empathic deficits has been shown to account for more variance in teacher-reported aggression than either construct alone (Schultz et al., 2004) and empathy (aggregated across child-, teacher-, and caregiver-reports) has been shown to predict less observed anger and aggression, respectively, in a group of 5-year-old children (Strayer \& Roberts, 2004). However, to the best of our knowledge, the potential for sympathy to buffer the anger-aggression link has not been investigated. Highly sympathetic children are more likely to anticipate and express concern for others (Eisenberg et al., 2014). This other-oriented concern is likely to operate in stark contrast to anger, for example, by highlighting the negative consequences of aggressive retaliation (see Eisenberg, 2000a).

In sum, past findings suggest that aggravating feelings of anger may interact with moral guilt and sympathy in multifaceted ways to determine the frequency and severity of aggression. Children who often feel guilt and sympathy may exhibit less anger-related aggression.

\section{The Present Study}

In the present study, we employed an ethnically diverse sample of 4-, 8-, and 12-yearolds to investigate guilt and sympathy as potential moderators of the anger-aggression link. In 
line with recent conceptual and empirical works outlining the differential/competing relations of moral emotions and anger to aggression (Arsenio, 2014; Lochman et al., 2010; Malti, 2015), we hypothesized that moral emotions would offset the anger-aggression link (i.e., that high anger would be associated with high aggression, but not for those with high levels of guilt or sympathy). To account for the well-established role of children's regulatory capacities in governing both anger and aggression, we controlled for inhibitory control, a self-regulatory aspect of temperament that involves preventing dominant, maladaptive responses, either under instruction or in novel/ambiguous situations (Rothbart \& Bates, 2006). We also accounted for socioeconomic status (SES) and sex in light of previous studies linking (a) SES to aggression (Dodge, Pettit, \& Bates, 1994), anger (Chen \& Matthews, 2001), and moral emotions (Eisenberg et al., 2014), and (b) sex to aggression (Archer, 2004), anger (Potegal \& Archer, 2004), and moral emotions (Malti, Gasser, \& Buchmann, 2009). Finally, we extended previous research to include early childhood, an understudied age group in this area, and considered potential age differences in our proposed relations because developmental differences in our study variables have been established in previous studies (see Maughan, Rowe, Messer, Goodman, \& Meltzer, 2004 for aggression; Murphy, Eisenberg, Fabes, Shepard, \& Guthrie, 1999 for anger; Malti, Eisenberg, Kim, \& Buchmann, 2013 for moral emotions).

\section{Method}

\section{Participants}

A community sample of 80 4-year-olds ( $M$ age $=4.48, S D=.37,39$ girls [49\%]), 808 year-olds $(M$ age $=8.47, S D=.24,42$ girls [53\%]), and 8212 -year-olds $(M$ age $=12.53, S D=$ $.36,40$ girls [49\%]) participated $(N=242,121$ girls [50\%]). All children were fluent in English (speaking and comprehension), as were their caregivers (speaking, comprehension, and writing). 
Families resided in a major Canadian city and were recruited from local community centers, events, and summer camps. As a proxy of SES, caregivers reported their highest level of education with the following breakdown: 7\% high school, $22 \%$ vocational, $55 \%$ bachelor's, and $14 \%$ master's/doctoral level (2\% chose not to report). This distribution was representative of the suburban region from which it was drawn (Statistics Canada, 2012). Ethnic composition included 34\% Western European, 12\% Eastern European, 11\% South Asian, 4\% Caribbean, 4\% East Asian, 3\% African, 3\% Central and South American, 3\% West and Central Asian, 3\% South East Asian, and $21 \%$ other/multiple origins (2\% chose not to report). The researchers' institution granted ethical approval.

\section{Procedure}

A pilot study $(N=11)$ was conducted to ensure age-appropriate assessment techniques and measures. Experimenters were undergraduate psychology students who received extensive training in both assessment techniques and procedures. For the present study, children and their caregivers attended the research laboratory for a single session. Written informed consent was obtained from caregivers and oral assent from children. Child interviews were conducted separately from caregivers in a designated room, lasted approximately 30 to 40 minutes, and were filmed for data analytic purposes. Caregivers remained in a waiting area and completed a questionnaire. At study end, they were debriefed while their child was awarded a certificate and an age-appropriate book.

\section{Measures}

Aggressive behavior. For 4-year-olds, 13 items from the narrow-band Aggressive Behavior syndrome scale of the Child Behavior Checklist (CBCL) for 1.5- to 5-year-olds (Achenbach \& Rescorla, 2000) were issued to caregivers in questionnaire format (e.g., "My child 
hits others"). For 8- and 12-year-olds, 13 items (carefully matched to those for 4-year-olds) from the analogous scale of the CBCL for 6- to 18-year-olds (Achenbach \& Rescorla, 2001) were issued (e.g., "My child gets in fights"). Items were rated on a 6-point scale ranging from $1=n o t$ at all true to $6=$ always true ( $\alpha$ s $=.85, .88$, and .70 for $4-, 8$-, and 12-year-olds, respectively).

Anger. Three items adapted by Eisenberg and colleagues (1993) from the affect intensity measure (AIM; Larsen \& Diener, 1987) tapping the intensity of children's angry emotions were issued to caregivers (e.g., "When my child gets angry, it is difficult for him/her to still be rational and not overreact"). Items were rated on a 7-point scale ranging from $1=$ never to $7=$ always and have been validated with samples from early childhood to adolescence (see Eisenberg, $2000 \mathrm{~b} ; \alpha \mathrm{s}=.65, .76$, and .73 for 4-, 8-, and 12-year-olds, respectively).

Moral Guilt. Children's guilt feelings were assessed in response to two hypothetical vignettes depicting moral transgressions (i.e., intentional harm). One involved the protagonist stealing from another child and the other involved him/her pushing another child. Both have been extensively validated by previous research in the happy-victimizer paradigm with samples ranging from early childhood to adolescence (Arsenio, 2014; Malti \& Ongley, 2014). They were accompanied by illustrations matched to the sex of the participating child and their wording was slightly modified to be appropriate for each age group. Two questions followed the interviewer's reading of each vignette: Question 1 asked, "How would you feel if you had done what (hypothetical victimizer's name) did?" If children said, "I don't know”, they were asked, "If you had (behavior of hypothetical victimizer), would you feel a little good, a little bad, or a little good and bad?" Answers to the latter prompt were recorded verbatim. For Question 2, children heard, "You said you would feel (emotion attribution from Question 1). How strongly would you feel (emotion attribution from Question 1)?" They answered this question by pointing to a visual, 3- 
point scale depicting squares of increasing size. Prior to this, 4-year-olds were calibrated with a similar scale depicting animals of increasing size (i.e., a mouse, horse, and elephant corresponding to low, medium, and high intensity emotions, respectively) to ensure they understood the scale format.

Coding moral guilt. The coding method was adapted from past research on children's moral emotions (Malti \& Ongley, 2014). For Question 1, children's anticipated emotions were coded as 1 (guilty) or 0 (not guilty). Specifically, bad, a little bad, sad, and guilty attributions were coded as 1 (guilty), while neutral, angry, happy, proud, good, a little good, other positive emotion, fearful, embarrassed/ashamed, and other negative emotion attributions were coded as 0 (not guilty). Including basic emotional correlates of guilt in our coding (bad, a little bad, sad) allowed us to examine moral emotion expectancies in younger children who may not be able to explicitly label complex feelings of guilt, but can name their basic emotional correlates and provide consonant moral reasoning (Malti \& Ongley, 2014; Tracy, Robins, \& Lagattuta, 2005). Due to minimal occurrence, psychosomatic complaint and other attributions were coded as missing. Two independent raters coded a random subsample $(n=24)$ of responses to Question 1 from both vignettes (Cohen's $\kappa$ was .99).

For Question 2, the intensity of children's guilt feelings was scored as follows: 1 if the child pointed to the smallest square (i.e., not strong guilt), 2 if the child pointed to the middlesized square (i.e., somewhat strong guilt), and 3 if the child pointed to the largest square (i.e., very strong guilt). A score of 0 was retained for not guilty attributions. Since intensity scores were positively correlated between vignettes, $r(228)=.17, p<.01$, we aggregated them and used the resulting continuous scores in analyses. High scores indicated high levels of guilt in anticipation of intentionally harming others. 
Children were also asked to provide reasons for their reported emotions, which were coded as 1 (moral), 2 (empathy), 3 (conflict resolution), 4 (sanctions), 5 (justification/hedonism), or 6 (other/undifferentiated; Malti \& Ongley, 2014). Categories 1 and 2 were both considered moral. For emotion coding, these reasons were consulted to clearly distinguish emotions in line with moral guilt (e.g., "sad because pushing is not fair... he was in line first") from amoral, negatively-valenced emotions (e.g., "bad because the other child was bothering me").

Sympathy. The child-reported sympathy scale consisted of five items from Zhou, Valiente, and Eisenberg (2003; e.g., "When I see someone being picked on, I feel sorry for them") depicting needy or unfortunate others that have shown meaningful relations to various measures of social behavior in developmental studies (e.g., Catherine \& Schonert-Reichl, 2011; Malti \& Ongley, 2014). Our pilot study ensured that 4-year-olds were able to comprehend and respond to the items in full capacity. After hearing each item, children were asked if it was "like [them] or not". If they indicated that the item was like them, they were asked if it was "really like [them]" or "sort of like [them]". Responses were coded as follows: "No, this does not sound like me" as 1 , "This is sort of like me" as 2 , and "This is really like me" as $3(\alpha \mathrm{s}=.85, .88$, and .72 for 4-, 8-, and 12-year-olds, respectively).

Inhibitory control. As a control variable, caregivers of 4-, 8-, and 12-year-olds completed items from the Inhibitory Control subscales of The Children's Behavior Questionnaire (CBQ; Rothbart, Ahadi, Hershey, \& Fisher, 2001; e.g., "My child can easily stop an activity when s/he is told 'no"'), The Temperament in Middle Childhood Questionnaire (TMCQ; Simonds \& Rothbart, 2004), and The Early Adolescent Temperament Questionnaire (EATQ; Capaldi \& Rothbart, 1992), respectively, on a 7-point scale ranging from $1=$ extremely untrue to $7=$ extremely true. We computed an aggregate score based on four, carefully matched items that 
tapped into similar facets across the scales $(\alpha s=.62, .65$, and .68 for 4-, 8-, and 12-year-olds, respectively).

\section{Results}

\section{Descriptive Statistics}

Table 1 displays the means and standard deviations of study variables by age group. A series of one-way ANOVAs revealed age differences in aggressive behavior, $F(2,238)=50.05$, $p<.001, \eta_{\mathrm{p}}{ }^{2}=.30$, anger, $F(2,238)=6.32, p<.01, \eta_{\mathrm{p}}{ }^{2}=.05$, and sympathy, $F(2,238)=97.55$, $p<.001, \eta_{\mathrm{p}}^{2}=.45$. Based on Bonferroni-corrected post-hoc comparisons, 4-year-olds were rated as more aggressive and reported less sympathy than 8 - and 12-year-olds ( $p s<.001)$, whereas 12 year-olds were rated lower in anger than $4-(p<.01)$ and 8-year-olds $(p<.05)$. Reports of guilt and inhibitory control did not significantly differ by age.

Zero-order correlations are displayed in Table 2. Notably, aggressive behavior was positively related to anger and sex (girls $=-0.5$; boys $=0.5$ ), and negatively to guilt, sympathy, inhibitory control, SES, and age. Inhibitory control was also negatively related to anger.

\section{Moderation Analyses}

We tested moral emotions as moderators of the relation between anger and aggression with a four-step hierarchical regression analysis in Mplus 7.11 (Muthén \& Muthén, 2012). Six children had missing values on our predictors and one was missing our dependent variable. To account for this missingness and thereby retain these children in our analysis, we used multiple imputation in Mplus 7.11 (Muthén \& Muthén, 2012; 25 imputed datasets; see Enders, 2010). At step 1 of the regression, we entered our control variables: (1) sex, (2) age, (3) SES, and (4) inhibitory control. At step 2, we entered (5) anger. At step 3, we entered (6) guilt and (7) sympathy. At step 4, we entered the interactions of (8) guilt x anger and (9) sympathy x anger. In 
line with Cohen, Cohen, West, and Aiken (2003), all variables at steps 1, 2, and 3 except for sex (coded -0.5 [girls] and 0.5 [boys]) were mean centered. See Table 3 for regression results. A considerable amount of variance in aggressive behavior was explained at step $1\left(R^{2}=.38, p<\right.$ .001). SES, age, and inhibitory control negatively predicted aggression, whereas sex was positively related to aggression. At step 2, the significant, positive effect of anger explained an additional $4 \%$ of variance $\left(R^{2}=.42, p<.001\right)$. At step 3 , sympathy (but not guilt) showed a significant, negative effect with a small increase $(1 \%)$ in explained variance $\left(R^{2}=.43, p<.001\right)$. At step 4, the interactions of guilt $\mathrm{x}$ anger and sympathy $\mathrm{x}$ anger added a further $2 \%$ in explained variance $\left(R^{2}=.45, p<.001\right.$; the unique contribution of each interaction was $\left.1 \%\right)$. Since the interaction of guilt $\mathrm{x}$ anger was statistically significant, we probed the effect of anger on aggressive behavior at low (-1SD), medium, and high (+1 SD) levels of guilt (Cohen et al., 2003). Anger was positively related to aggressive behavior at low $(b=.20, p<.001)$ and medium $(b=.14, p<.001)$ but not high $(b=.08, p=.09)$ levels of guilt (see Figure 1). The interaction of sympathy $\mathrm{x}$ anger was only marginally significant, although its effect size and simple slopes results were virtually identical to those of guilt: Anger was positively related to aggressive behavior at low $(b=.20, p<.001)$ and medium $(b=.14, p<.001)$ but not high $(b=$ $.08, p=.11$ ) levels of sympathy (see Figure 2).

As a final (i.e., fifth) step, we investigated age differences in the moderating effects of guilt and sympathy by testing the three-way interactions of guilt $\mathrm{x}$ anger $\mathrm{x}$ age and sympathy $\mathrm{x}$ anger $\mathrm{x}$ age. Since neither of which were significant, we dropped them from the final model.

\section{Discussion}

The negative short- and long-term implications of anger and aggression manifest directly as fighting and violence (Arsenio \& Lemerise, 2010), and indirectly as learning difficulties 
(Brennan et al., 2012) and social adjustment issues (Ladd et al., 2014) across development. As such, mitigating the anger-aggression link represents an important avenue for educators to improve the behavioral functioning and well being of children and adolescents. Amoral anger and the moral emotions of guilt and sympathy have been recognized as important predictors of children's aggression (Cooley, Elenbaas, \& Killen, 2012; Malti, Killen, \& Gasser, 2012; Schultz et al., 2004), but their interaction in predicting aggressive outcomes has not been empirically detailed. The present study was the first to investigate moral guilt and sympathy as potential moderators of the anger-aggression link in an ethnically diverse sample of 4-, 8- and 12-yearolds.

We found that anger was positively related to aggression, which corroborates a large body of existing literature (see Lochman et al., 2010) and adds further support to longstanding theorizing that intense feelings of anger are externalized through aggressive acts (Berkowitz, 1989). Also in line with previous research (e.g., Schultz et al., 2004; Strayer \& Roberts, 2004), we found that sympathy was negatively related to aggressive behavior, which lends further support to theoretical models emphasizing the protective function of other-oriented, sympathetic concern (i.e., its role in highlighting the negative consequences of moral transgressions and dissuading aggressive conduct; Eisenberg et al., 2014).

Unlike previous studies (see Malti \& Krettenauer, 2013), guilt was not independently related to aggression in our multiple regression analysis. This suggests that the other emotions we controlled for in our model (i.e., anger and sympathy) have stronger direct relations to aggressive behavior. However, moral guilt did moderate the relation of anger and aggression. High anger was associated with high aggression, but not for children and adolescents with high guilt. In other words, those who felt more intense guilt following transgressions exhibited less 
anger-related aggression. Feelings of guilt in anticipation of intentionally harming others may outweigh feelings of anger that would otherwise lead to aggression. Instead of externalizing anger towards others (e.g., via aggressive retaliation), children with high levels of guilt may be more inclined to internalize angry feelings in anticipation of violating their moral norms. It is also possible that children's guilt feelings shift their attention away from anger-inducing stimuli by highlighting the moral salience of situations and decreasing the attractiveness of aggressive reactions (Eisenberg, 2000a; Malti \& Latzko, 2012). Finally, the personal relevance of guilt may enhance its role in guiding behavioral outcomes (see Hoffman, 2000), as it could be argued that internalized guilt feelings hold more intrinsic value than anger that stems from an external source. However, we are aware that ad hoc studies with experimental manipulations are needed to provide more direct empirical support for these assumptions. To further understand how and why guilt feelings disrupt the anger-aggression link, extensions of the present study should assess these variables as a sequence of cascading and interrelated events.

We found a similar interaction between sympathy and anger in predicting aggression that, albeit marginally significant, was identical in effect size to the interaction of guilt and anger. As hypothesized, high levels of anger were unrelated to aggression when children had high sympathy. Feelings of other-oriented, sympathetic concern may help children connect externalized anger with its negative social consequences and thereby prompt them to anticipate and curb anger-related aggression (see Eisenberg, 2000a for a similar argument). Those who lack sympathetic concern, on the other hand, may favor the immediate, cathartic benefits of externalizing anger through aggressive behavior.

It was important for us to consider that self-control, rather than moral emotions, could have been responsible for our proposed effects. This had previously been unaccounted for in 
related research (i.e., Tangney et al., 1996). Inhibitory control (i.e., the capacity to control impulses and delay gratification) is thought to protect against problem behavior by promoting the development and use of social-information processing (Frick \& Morris, 2004) and facilitating positive interactions with caregivers and peers (Eisenberg et al., 2010). Past studies have linked inhibitory control to low levels of anger (Frick \& Morris, 2004) and aggression (Eisenberg et al., 2010). By partialling out these effects, we were able to highlight the anger-aggression buffering qualities of moral emotions above and beyond those of inhibitory control.

Interestingly, we did not find developmental differences in the moderating effects of guilt and sympathy, suggesting that moral emotions operate as anger-aggression buffers from a young age and maintain this role up to early adolescence. This resonates with meta-analytic data demonstrating a consistent relationship between moral emotion attributions and aggression from 4 to 20 years of age (Malti \& Krettenauer, 2013). We did, however, uncover mean-level developmental differences in aggression, anger, and sympathy, respectively. Consistent with past research citing normative decreases in aggressive behavior from the preschool years to middle childhood (Maughan et al., 2004), 4-year-olds in our study were rated as more aggressive than 8and 12-year-olds. Twelve-year-olds received lower anger ratings than 4- and 8-year-olds, which agrees with past longitudinal data citing a decrease in negative emotionality from the middle school to late elementary years (Murphy et al., 1999). In line with previous studies documenting increases in sympathy from early to middle childhood (Eisenberg et al., 2014; Malti et al., 2013), 8- and 12-year-olds reported more sympathy than 4-year-olds, which may be attributed (in part) to increases in perspective taking from early to late childhood (Hoffman, 2000). Also in line with previous studies (see Eisenberg, 2005), no age differences in inhibitory control were reported, 
which further supports the notion that regulatory capacities are a relatively stable facet of child temperament (see Rothbart \& Bates, 2006).

Despite a number of strengths, there are limitations of this study that future research should overcome. Although we utilized an ethnically diverse, relatively large sample and employed a mixed-method (e.g., questionnaires and vignettes), multi-informant (i.e., children and caregivers) approach that strengthened our findings by reducing the chance of undesirable biases (e.g., common method variance), the cross-sectional nature of our data did not allow for temporal inferences. While we do believe that our findings uphold the possibility (or at least point in the direction) that aggression-related anger is disrupted by moral feelings, more studies are needed to extend our findings. For example, studies using longitudinal designs should systematically investigate changes in moral emotions as they relate to changes in the angeraggression link (preferably within the same situation). Also, the effect sizes of our moderating relations were small according to standard criteria (Cohen, 1988), which should be considered in light of us controlling for a number of other factors known to influence our study variables (i.e., age, sex, SES, and inhibitory control). Although small effects can have meaningful, practical significance (Cohen et al., 2003), we believe that experimental studies with manipulations to delineate the roles of moral emotions can shed further light on their relative importance in buffering the well-established anger-aggression link.

Despite these limitations, the present study was the first to comprehensively assess and demonstrate the roles of moral guilt and sympathy in moderating the anger-aggression relations of 4-, 8-, and 12-year-olds. In their everyday lives, children encounter multifaceted social conflict situations that elicit a diverse range of emotions - from amoral to moral. If educators and practitioners are able to tip the affective scales of children displaying aggressive behavior away 
from anger and towards moral feelings of guilt and sympathy, they may help them navigate towards prosocial solutions to conflicts. 


\section{References}

Achenbach, T. M., \& Rescorla, L. A. (2000). Manual for the ASEBA preschool forms \& profiles. Burlington, VT: University of Vermont, Research Center for Children, Youth, \& Families.

Achenbach, T. M., \& Rescorla, L. A. (2001). Manual for the ASEBA school-age forms \& profiles. Burlington, VT: University of Vermont, Research Center for Children, Youth, \& Families.

Archer, J. (2004). Sex differences in aggression in real-world settings: A meta-analytic review. Review of General Psychology, 8(4), 291-322. doi:10.1037/1089-2680.8.4.291

Arsenio, W. (2014). Moral emotion attributions and aggression. In M. Killen \& J. Smetana (Eds.), Handbook of moral development (2nd ed., pp. 235-255). New York, NY: Psychology Press.

Arsenio, W. F., Cooperman, S., \& Lover, A. (2000). Affective predictors of preschoolers' aggression and peer acceptance: Direct and indirect effects. Developmental Psychology, 36(4), 438-448. doi:10.1037/0012-1649.36.4.438

Arsenio, W. F., \& Lemerise, E. A. (2010). Emotions, aggression, and morality in children: Bridging development and psychopathology. Washington, DC: American Psychological Association.

Berkowitz, L. (1989). Frustration-aggression hypothesis: Examination and reformulation. Psychological Bulletin, 106, 59-73. doi:10.1037/0033-2909.106.1.59

Blair, R. J. R. (2010). Empathy, moral development, and aggression: A cognitive neuroscience perspective. In W. F. Arsenio \& E. A. Lemerise (Eds.), Emotions, aggression, and 
morality in children: Bridging development and psychopathology (pp. 97-114).

Washington, DC: American Psychological Association.

Brennan, L. M., Shaw, D. S., Dishion, T. J., \& Wilson, M. (2012). Longitudinal predictors of school-age academic achievement: Unique contributions of toddler-age aggression, oppositionality, inattention, and hyperactivity. Journal of Abnormal Child Psychology, 40(8), 1289-1300. doi:10.1007/s10802-012-9639-2

Capaldi, D. M., \& Rothbart, M. K. (1992). Development and validation of an early adolescent temperament measure. The Journal of Early Adolescence, 12(2), 153-173.

Catherine, N. L. A., \& Schonert-Reichl, K. (2011). Children's perceptions and comforting strategies to infant crying: Relations to age, sex, and empathy-related responding. British Journal of Developmental Psychology, 29(3), 524 -551. doi:10.1348/026151010X521475

Chen, E., \& Matthews, K. A. (2001). Cognitive appraisal biases: An approach to understanding the relation between socioeconomic status and cardiovascular reactivity in children. Annals of Behavioral Medicine, 23(2), 101-111.doi:10.1207/S15324796ABM2302_4

Cohen, J. (1988). Statistical power analysis for the behavioral sciences (2nd ed.). Hillsdale, NJ: Lawrence Earlbaum Associates.

Cohen, J., Cohen, P., West, S. G., \& Aiken, L. S. (2003). Applied multiple regression/correlation analysis for the behavioural sciences (3rd ed.). Mahwah, NJ: Lawrence Erlbaum.

Cohen, M. A., \& Piquero, A. R. (2009). New evidence on the monetary value of saving a high risk youth. Journal of Quantitative Criminology, 25(1), 25-49. doi:10.1007/s10940-0089057-3 
Cooley, S., Elenbaas, L., \& Killen, M. (2012). Moral judgments and emotions: Adolescents' evaluations in intergroup social exclusion contexts. New Directions for Youth Development, 136, 41-57. doi:10.1002/yd.20037

Dinolfo, C., \& Malti, T. (2013). Interpretive understanding, sympathy, and moral emotion attribution in oppositional defiant disorder symptomatology. Child Psychiatry and Human Development, 44(5), 633-645. doi:10.1007/s10578-013-0357-y

Dodge, K. A., Pettit, G. S., \& Bates, J. E. (1994). Socialization mediators of the relation between socioeconomic status and child conduct problems. Child Development, 65(2), 649-665.

Eisenberg, N. (2000a). Empathy and sympathy. In M. Lewis \& J. M. Haviland-Jones (Eds.), Handbook of emotions (2nd ed., pp. 677-691). New York, NY: Guilford Press.

Eisenberg, N. (2000b). Emotion, regulation, and moral development. Annual Review of Psychology, 51, 665-697. doi:10.1146/annurev.psych.51.1.665.

Eisenberg, N. (2005). Temperamental effortful control (self-regulation). In R. E. Tremblay, R. G. Barr, \& R. DeV. Peters (Eds.), Encyclopaedia on early childhood development [online]. Montreal, QC: Centre of Excellence for Early Childhood Development.

Eisenberg, N., Fabes, R. A., Bernzweig, J., Karbon, M., Poulin, R., \& Hanish, L. (1993). The relations of emotionality and regulation to preschoolers' social skills and sociometric status. Child Development, 64, 1418-1438.

Eisenberg, N., Fabes, R. A., Murphy, B. C., Shepard, S., Guthrie, I. K., Mazsk, P., . . Jones, S. (1999). Prediction of elementary school children's socially appropriate and problem behavior from anger reactions at age 4-6 years. Journal of Applied Developmental Psychology, 20(1), 119-142. doi:10.1016/S0193-3973(99)80007-0 
Eisenberg, N., Spinrad, T. L., \& Eggum, N. D. (2010). Emotion-related self-regulation and its relation to children's maladjustment. Annual Review of Clinical Psychology, 6, 495-525. doi:10.1146/annurev.clinpsy.121208.131208

Eisenberg, N., Spinrad, T. L., \& Morris, A. (2014). Empathy-related responding in children. In M. Killen \& J. Smetana (Eds.), Handbook of moral development (2nd ed., pp. 184-207). New York, NY: Psychology Press.

Eisner, M.P., \& Malti, T. (2015). Aggressive and violent behavior. In M. E. Lamb (Vol. Ed.) \& R. M. Lerner (Ser. Ed.), Handbook of child psychology and developmental science, Vol. 3: Social, emotional and personality development (7th ed., pp. 795-884). New York, NY: Wiley.

Enders, C. K. (2010). Applied missing data analysis. New York, NY: Guilford Press.

Frick, P. J., (2012). Developmental pathways to conduct disorder: Implications for future directions in research, assessment, and treatment. Journal of Clinical Child and Adolescent Psychology, 41, 378-389. doi:10.1080/15374416.2012.664815

Frick, P. J., \& Morris, A. S. (2004). Temperament and developmental pathways to conduct problems. Journal of Clinical Child and Adolescent Psychology, 33(1), 54-68. doi:10.1207/S15374424JCCP3301_6

Hoffman, M. L. (2000). Empathy and moral development: Implications for caring and justice. New York, NY: Cambridge University Press.

Hubbard, J. A., Romano, L. J., McAuliffe, M. D., \& Morrow, M. T. (2010). Anger and the reactive-proactive aggression distinction in childhood and adolescence. In M. Potegal, G. Stemmler, \& C. Spielberger (Eds.), International handbook of anger: Constituent and concomitant biological, psychological, and social processes. New York, NY: Springer. 
Hubbard, J. A., Smithmyer, C. M., Ramsden, S. R., Parker, E. H., Flanagan, K. D., Dearing, K. F., ... Simons, R. F. (2002). Observational, physiological, and self-report measures of children's anger: Relations to reactive versus proactive aggression. Child Development, 73(4), 1101-1118. doi:10.1111/1467-8624.00460

Kochanska, G., Gross, J. N., Lin, M., \& Nichols, K. E. (2002). Guilt in young children: Development, determinants, and relations with a broader system of standards. Child Development, 73(2), 461-482. doi:10.1111/1467-8624.00418

Krahé, B. (2013). The social psychology of aggression (2nd ed.). New York, NY: Psychology Press.

Ladd, G. W., Ettekal, I., Kochenderfer- Ladd, B., Rudolph, K. D., \& Andrews, R. K. (2014). Relations among chronic peer group rejection, maladaptive behavioral dispositions, and early adolescents' peer perceptions. Child Development, 85(3), 971-988. doi:10.1111/cdev.12214

Larsen, R. J., \& Diener, E. (1987). Affect intensity as an individual difference characteristic: A review. Journal of Research in Personality, 21, 1-39.

Lazarus, R. S. (1991). Progress on a cognitive-motivational-relational theory of emotion. American Psychologist, 46, 819-834. doi:10.1037/0003-066X.46.8.819

Lerner, J. V., Hertzog, C., Hooker, K. A., Hassibi, M., \& Thomas, A. (1988). A longitudinal study of negative emotional states and adjustment from early childhood through adolescence. Child Development, 59(2), 356-366.

Lochman, J. E., Barry, T., Powell, N., \& Young, L. (2010). Anger and aggression. In D. W. Nangle, D. J. Hansen, C. A. Erdley, \& P. J. Norton (Eds.). Practitioner's guide to empirically based measures of social skills (pp. 155-166). New York, NY: Springer. 
Malti, T. (2007). Moral emotions and aggressive behavior in childhood. In G. Steffgen \& M. Gollwitzer (Eds.), Emotions and aggressive behavior (pp. 176-191). Göttingen, DE: Hogrefe.

Malti, T. (2015). Toward an integrated clinical-developmental model of guilt from early childhood to adolescence. Manuscript submitted for publication.

Malti, T., Eisenberg, N., Kim, H., \& Buchmann, M. (2013). Developmental trajectories of sympathy, moral emotion attributions, and moral reasoning: The role of parental support. Social Development, 22(4). 773-793. doi:10.1111/sode.12031

Malti, T., Gasser, L., \& Buchmann, M. (2009). Aggressive and prosocial children's emotion attributions and moral reasoning. Aggressive Behavior, 35, 90-102. doi:10.1002/ab.20289

Malti, T., Killen, M., \& Gasser, L. (2012). Social judgments and emotion attributions about exclusion in Switzerland. Child Development, 83(2), 697-711. doi:10.1111/j.14678624.2011.01705.x

Malti, T., \& Krettenauer, T. (2013). The relation of moral emotion attributions to prosocial and antisocial behavior: A meta-analysis. Child Development, 84(2), 397-412. doi:10.1111/j.1467-8624.2012.01851.x

Malti, T., \& Latzko, B. (2012). Moral emotions. In V. Ramachandran (Ed.), Encyclopedia of human behavior (2nd ed., pp. 644-649). Maryland Heights, MO: Elsevier.

Malti, T., \& Ongley, S. (2014). The development of moral emotions and moral reasoning. In M. Killen \& J. Smetana (Eds.), Handbook of moral development (2nd ed., pp. 163-183). New York, NY: Psychology Press. 
Maughan, B., Rowe, R., Messer, J., Goodman, R., \& Meltzer, H. (2004). Conduct disorder and oppositional defiant disorder in a national sample: Developmental epidemiology. Journal of Child Psychology and Psychiatry, 45, 609-621. doi:10.1111/j.1469-7610.2004.00250.x

Montada, L., \& Schneider, A. (1989). Justice and emotional reactions to the disadvantaged. Social Justice Research, 3(4), 313-344. doi:10.1007/BF01048081

Murphy, B. C., Eisenberg, N., Fabes, R. A., Shepard, S., \& Guthrie, I. K. (1999). Consistency and change in children's emotionality and regulation: A longitudinal study. MerrillPalmer Quarterly, 45(3), 413-444.

Muthén, L. K., \& Muthén, B. O. (2012). Mplus user's guide (7th ed.). Los Angeles, CA: Muthén \& Muthén.

Potegal, M., \& Archer, J. (2004). Sex differences in childhood anger and aggression. Child and Adolescent Psychiatric Clinics of North America, 13(3), 513-528. doi:10.1016/j.chc.2004.02.004

Rothbart, M. K., Ahadi, S. A., Hershey, K. L., \& Fisher, P. (2001). Investigations of temperament at three to seven years: The Children's Behavior Questionnaire. Child Development, 72(5), 1394-1408. doi:10.1111/1467-8624.00355

Rothbart, M. K., \& Bates, J. E. (2006). Temperament. In W. Damon, R. Lerner, \& N. Eisenberg (Eds.), Handbook of child psychology: Vol. 3, Social, emotional, and personality development (6th ed., pp. 99-166). New York, NY: Wiley Press.

Schultz, D., Izard, C. E., \& Bear, G. (2004). Children's emotion processing: Relations to emotionality and aggression. Development and Psychopathology, 16, 371-387. doi:10.1017/S0954579404044566 
Simonds, J., \& Rothbart, M. K. (2004, October). The Temperament in Middle Childhood Questionnaire (TMCQ): A computerized self-report measure of temperament for ages 7 10. Poster session presented at the Occasional Temperament Conference, Athens, GA.

Strayer, J., \& Roberts, W. (2004). Empathy and observed anger and aggression in five-year-olds. Social Development, 13(1), 1-13. doi:10.1111/j.1467-9507.2004.00254.x

Tangney, J. P., Stuewig, J., \& Mashek, D. J. (2007). Moral emotions and moral behavior. Annual Review of Psychology, 58, 345-372. doi:10.1146/annurev.psych.56.091103.070145

Tangney, J. P., Wagner, P. E., Hill-Barlow, D., Marschall, D. E., \& Gramzow, R. (1996). Relation of shame and guilt to constructive versus destructive responses to anger across the lifespan. Journal of Personality and Social Psychology, 70(4), 797-809. doi:10.1037/0022-3514.70.4.797

Tracy, J. L., Robins, R. W., \& Lagattuta, K. H. (2005). Can children recognize pride? Emotion, 5(3), 251-257. doi:10.1037/1528-3542.5.3.251

Zhou, Q., Valiente, C., \& Eisenberg, N. (2003). Empathy and its measurement. In S. J. Lopez \& C. R. Snyder (Eds.), Positive psychological assessment: A handbook of models and measures (pp. 269-284). Washington, DC: American Psychological Association. 
Table 1

Means and Standard Deviations of Study Variables by Age Group

\begin{tabular}{|c|c|c|c|}
\hline & 4-year-olds & 8-year-olds & 12-year-olds \\
\hline Variables & $M(S D)$ & $M(S D)$ & $M(S D)$ \\
\hline Aggressive behavior & $2.57(0.76)$ & $1.74(0.54)$ & $1.69(0.55)$ \\
\hline Anger & $4.66(1.15)$ & $4.51(1.05)$ & 4.05 (1.19) \\
\hline Moral guilt & $1.13(1.02)$ & $1.33(1.02)$ & $1.38(0.96)$ \\
\hline Sympathy & $1.60(0.51)$ & $2.37(0.48)$ & $2.51(0.34)$ \\
\hline Inhibitory control & $4.87(1.12)$ & $4.79(1.14)$ & $4.91(1.11)$ \\
\hline
\end{tabular}

Note. Caregiver-reported: aggressive behavior, anger, and inhibitory control. Child-reported: guilt and sympathy. Scale ranges: aggressive behavior (1-6), anger and inhibitory control (1-7), guilt (0-3), and sympathy (1-3). 
Table 2

Correlations between Study and Control Variables

\begin{tabular}{|c|c|c|c|c|c|c|c|c|}
\hline Variables & 1 & 2 & 3 & 4 & 5 & 6 & 7 & 8 \\
\hline 1. Aggressive behavior & - & & & & & & & \\
\hline 2. Anger & $.40^{* *}$ & - & & & & & & \\
\hline 3. Moral guilt & $-.13^{*}$ & .02 & - & & & & & \\
\hline 4. Sympathy & $-.43^{* *}$ & $-.15^{*}$ & $.12^{\dagger}$ & - & & & & \\
\hline 5. Inhibitory control & $-.36^{* *}$ & $-.34^{* *}$ & .10 & .10 & - & & & \\
\hline 6. SES & $-.15^{*}$ & $-.21^{* *}$ & -.01 & $.12^{\dagger}$ & .07 & - & & \\
\hline 7. Age & $-.49^{* *}$ & $-.21^{* *}$ & .10 & $.62^{* *}$ & .02 & .06 & - & \\
\hline 8. Sex & $.13^{*}$ & -.04 & $-.13^{*}$ & $-.15^{*}$ & $-.14^{*}$ & $.13^{*}$ & .01 & - \\
\hline
\end{tabular}


Table 3

Regression Analysis with Aggressive Behavior as Dependent Variable

\begin{tabular}{|c|c|c|c|c|}
\hline \multirow[t]{2}{*}{ Variables } & Step 1 & Step 2 & Step 3 & Step 4 \\
\hline & $\beta$ & $\beta$ & $\beta$ & $\beta$ \\
\hline 1. Sex & $.10^{*}$ & $.12 *$ & $.09 *$ & $.09^{\dagger}$ \\
\hline 2. Age & $-.47 * *$ & $-.43 * *$ & $-.35 * *$ & $-.35 * *$ \\
\hline 3. SES & $-.12 *$ & $-.09^{\dagger}$ & -.08 & -.08 \\
\hline 4. Inhibitory control & $-.33 * *$ & $-.26 * *$ & $-.24 * *$ & $-.24 * *$ \\
\hline 5. Anger & - & $.21 * *$ & $.21 * *$ & $.22 * *$ \\
\hline 6. Moral guilt & - & - & -.06 & -.05 \\
\hline 7. Sympathy & - & - & $-.12 *$ & -.10 \\
\hline 8. Moral guilt x Anger & - & - & - & $-.09 *$ \\
\hline 9. Sympathy x Anger & - & - & - & $-.09^{\dagger}$ \\
\hline$R^{2}$ & .38 & $.42\left(\Delta R^{2}=.04\right)$ & $.43\left(\Delta R^{2}=.01\right)$ & $.45\left(\Delta R^{2}=.02\right)$ \\
\hline
\end{tabular}

Note. Standardized regression coefficients $(\beta)$ and variance explained at each step $\left(R^{2}\right)$. Sex = girls $(-0.5)$, boys $(0.5)$. ${ }^{* *} p<.01, \stackrel{*}{p} \leq .05, \stackrel{\dagger}{\dagger}<.10$. 


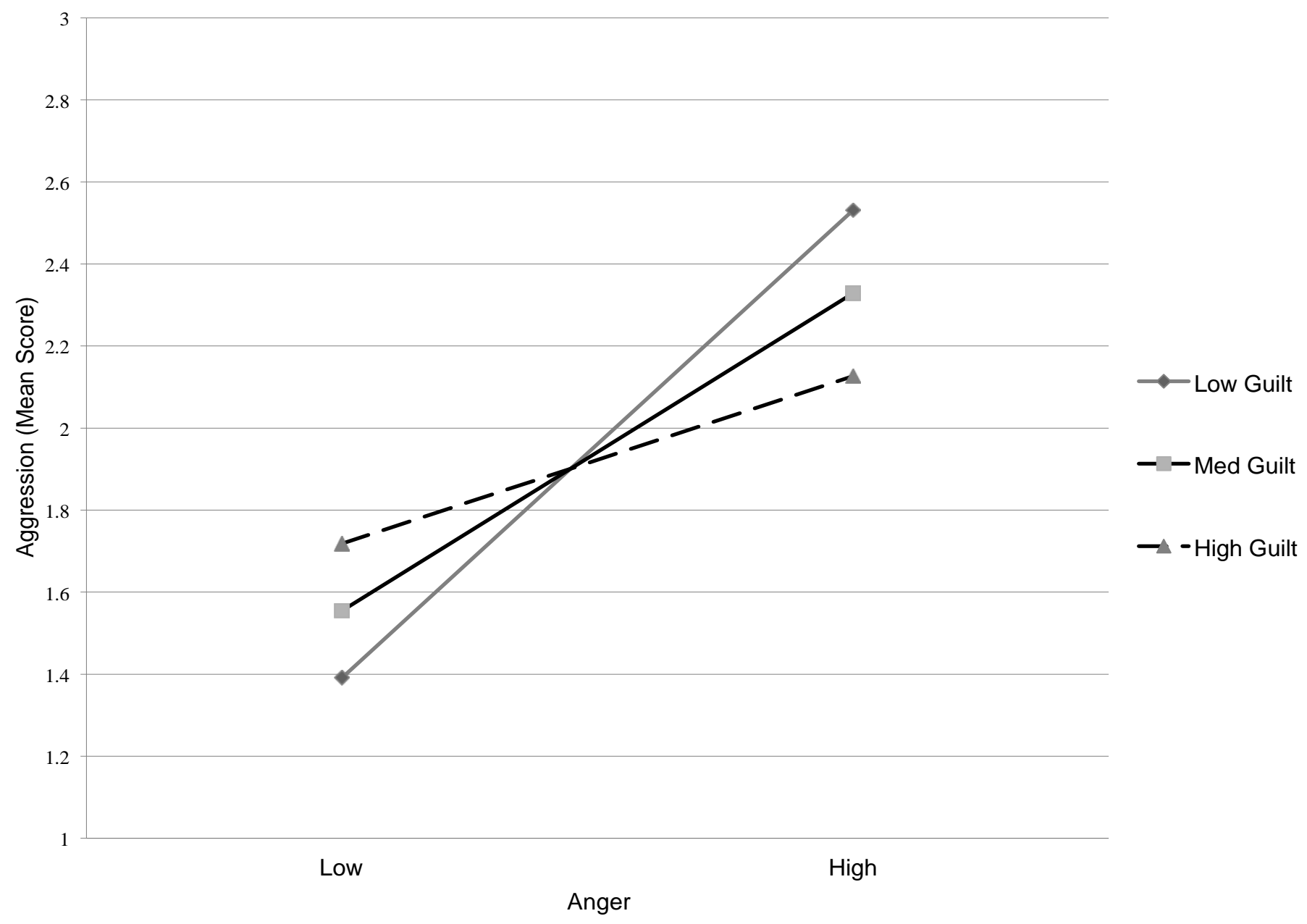

Figure 1. Anger in relation to aggression at low (-1 SD), medium, and high $(+1 S D)$ moral guilt. Note. Dotted line represents non-significant effect. 


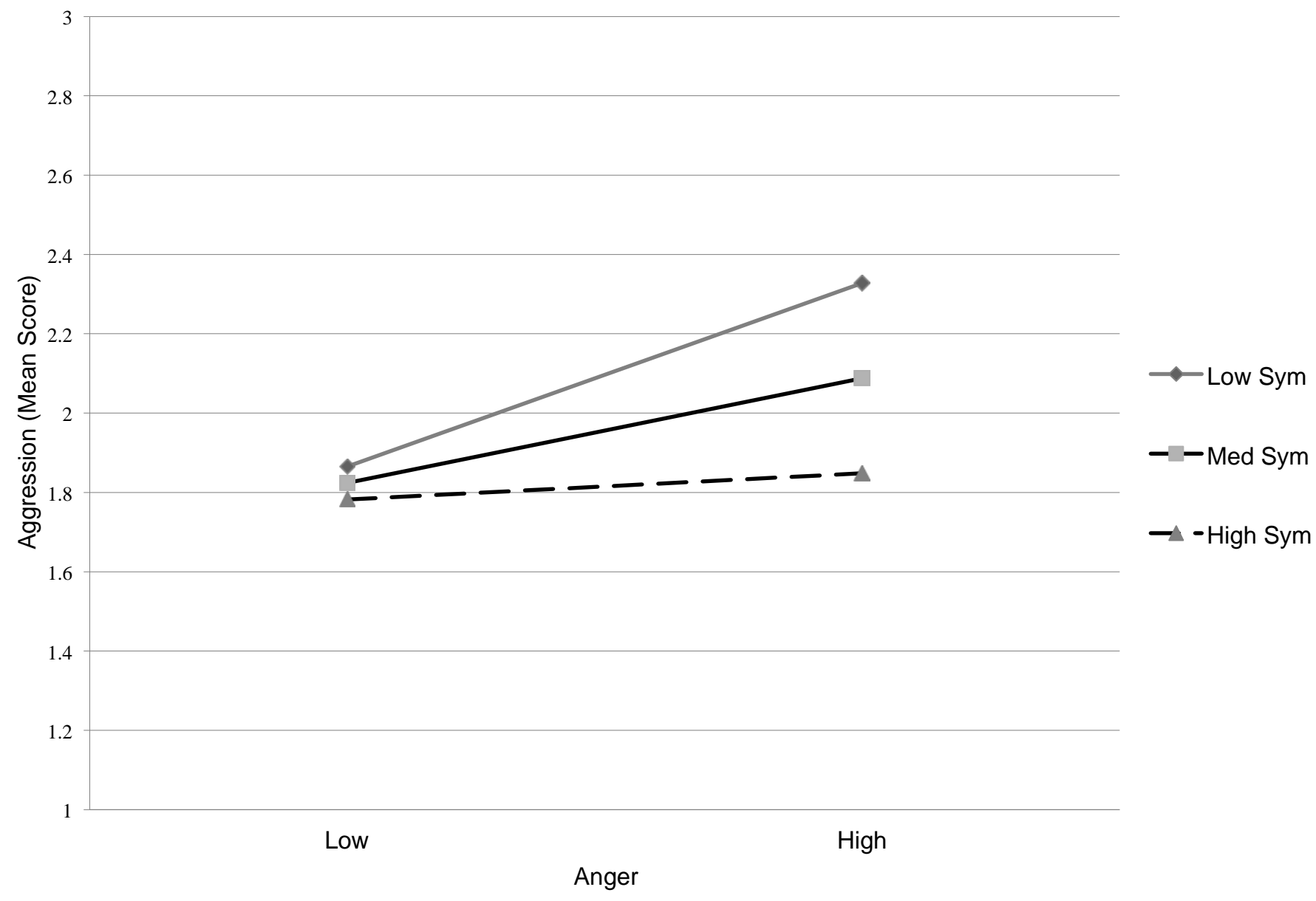

Figure 2. Anger in relation to aggression at low (-1 SD), medium, and high (+1 SD) sympathy. Note. Dotted line represents non-significant effect. 